\title{
Translation and validation of the Turkish version of the Psychosocial Impact of Dental Aesthetics Questionnaire
}

\author{
Cahide Aglarci ${ }^{\mathrm{a}}$ \\ Asli Baysal ${ }^{\mathrm{b}}$ \\ Kadir Demircic \\ Ferhan Dikmen ${ }^{\mathrm{a}}$ \\ Ali Vasfi Aglarci ${ }^{\mathrm{d}}$
}

${ }^{\mathrm{a}}$ Department of Orthodontics, Faculty of Dentistry, Sifa University, lzmir, Turkey

${ }^{b}$ Department of Orthodontics, Faculty of Dentistry, Katip Celebi University, lzmir, Turkey

'Department of Psychiatry, Faculty of Medicine, Suleyman Demirel University, Isparta, Turkey

${ }^{\mathrm{d}}$ Department of Biostatistics, Faculty of Medicine, Suleyman Demirel University, Isparta Turkey
Objective: The aim of this study was to translate the Psychosocial Impact of Dental Aesthetics Questionnaire (PIDAQ) into Turkish, validate the questionnaire, and provide a cross-cultural adaptation. Methods: The translation process included the following steps, which were performed by a translation committee: (1) translation into Turkish, (2) back translation into English, (3) pretesting, and (4) cross-cultural adaptation. The Turkish version of the PIDAQ was produced subsequent to the translation process. Validity and reliability were measured using the Perception of Occlusion Scale and the aesthetic component of the Index of Orthodontic Treatment Need. The questionnaire was administered to 260 individuals (age range, 18-30 years; mean age, $20.50 \pm 1.9$ years). Structural validity was assessed via factor analysis, and internal consistency was measured using Cronbach's alpha coefficient. Results: Factor analysis revealed a four-factor structure, with factor loadings for included items ranging from 0.380 to 0.868 . Few questions were shuffled among domains various factor loadings. Cronbach's alphas for the Turkish version of the PIDAQ ranged from 0.534 to 0.904. Mean scores for the PIDAQ subscale and total scores differed significantly according to Index of Orthodontic Treatment Need and Perception of Occlusion Scale scores. Conclusions: This study provided a Turkish version of the PIDAQ, which could be a useful tool in the evaluation of the psychosocial impact of malocclusion in young Turkish adults.

[Korean J Orthod 2016;46(4):220-227]

Key words: Esthetics, Perception, Psychology

Received October 30, 2015; Revised December 2, 2015; Accepted December 14, 2015.

Corresponding author: Cahide Aglarci.

Assistant Professor, Department of Orthodontics, Faculty of Dentistry, Sifa University, lzmir, Turkey.

Tel+90-2323080000 e-mail cahide@gmail.com

The authors report no commercial, proprietary, or financial interest in the products or companies described in this article.

(C) 2016 The Korean Association of Orthodontists.

This is an Open Access article distributed under the terms of the Creative Commons Attribution Non-Commercial License (http://creativecommons.org/licenses/by-nc/4.0) which permits unrestricted non-commercial use, distribution, and reproduction in any medium, provided the original work is properly cited. 


\section{INTRODUCTION}

Oral health affects people physically, as it is closely related to appearance, enjoyment, eating, speech, taste, and growth. 'In addition, it exerts a strong influence on socialization and social well-being; therefore, the psychological effects of oral health should be evaluated. Disruption to psychological and social functioning, in addition to physical functioning, is important in assessing oral health. In other words, oral health should be defined according to psychological and social wellbeing as well as physical factors. Traditional measures should be supported using measures of oral healthrelated quality of life in sociodental approaches to assessing treatment need. ${ }^{2}$

Increasing demand for orthodontic treatment could be attributed to dental aesthetics and its psychological effects. ${ }^{3,4}$ Generally, patient expectations of orthodontic treatment include improvements in appearance, selfimage, and social functioning. ${ }^{5,6}$ From an orthodontic perspective, malocclusion affects oral function and appearance and exerts a crucial social and psychological impact. ${ }^{3,7}$ However, professionals generally evaluate orthodontic treatment need using tools such as normal occlusion and cephalometric measurements, disregarding the impact of malocclusion on patients' oral healthrelated quality of life (OHRQOL). ${ }^{8}$

In the last decade, patients' perceptions of aesthetics during orthodontic treatment planning has become an interesting topic from a psychological perspective. ${ }^{7,9}$ In addition, the use of OHRQOL measurement tools and occlusal indices has been reported to be effective in predicting orthodontic concerns. ${ }^{10}$ Questionnaires are frequently used in the assessment of OHRQOL and offer information concerning patients' perceptions of their welfare in relation to particular oral conditions." Klages et al. ${ }^{5}$ developed the Psychosocial Impact of Dental Aesthetics Questionnaire (PIDAQ) to measure orthodontics-related OHRQOL. This self-rating instrument could be also used to assess orthodontic treatment need and evaluate changes in OHRQOL subsequent to orthodontic treatment. ${ }^{4,5}$

Prior to using questionnaires in different cultures, the implementation of a translation and validation process that takes the cultural and social aspects of the new region into consideration is essential to measure the same constructs with the same accuracy. ${ }^{7}$ The PIDAQ has been used widely and translated into several languages, and it has demonstrated good validity and reliability; however, it has not been translation into Turkish., ${ }^{4,6,7,12,13}$

To our knowledge, there are no psychological scales to assess orthodontics-related OHRQOL published in Turkish. Therefore, a Turkish version of PIDAQ could be the first such scale in this field of research. The aim of this study was to translate the PIDAQ into Turkish, validate the questionnaire, and provide a cross-cultural adaptation.

\section{MATERIALS AND METHODS}

Ethical approval was obtained prior to initiation of the study from Ethical Committee of Sifa University (ref.: 251-68). All participants were volunteers and provided written informed consent. Participants were undergraduate students from the Faculty of Medicine of Sifa University (lzmir, Turkey). Despite the convenience in sampling, our sample represented different parts of the country, as the institute is in the third-largest city in Turkey. Dentistry faculty students and foreign citizens were excluded from the study. The exclusion criteria were as follows; 1) previous orthodontic treatment, 2) missing or fractured teeth in the anterior region, 3) discoloration in the anterior region, and 4) craniofacial anomaly. In total, the study included 284 individuals, of whom 24 were excluded because of missing data or the provision of more than one answer per questionnaire item. Therefore, the analysis included data from 260 students. The scales were administered in random order, but the informed consent form always appeared first.

\section{Description of the Turkish version of PIDAQ}

The PIDAQ is a 23-item psychometric scale composed of four subscales divided according to one positive and three negative domains: aesthetic concern ( 3 items), psychological impact (6 items), social impact (8 items), and dental self-confidence ( 6 items). Responses are provided using a five-point likert scale ranging from 0 (not at all) to 4 (very strongly), which represents the extent of the impact of dental aesthetics on quality of life. ${ }^{5}$

\section{Translation}

The permission required to translate the PIDAQ into Turkish was received from one of the developers of the scale (Dr. Andrej Zentner) via e-mail. The scale was translated to Turkish by an orthodontist and a linguist. Another orthodontist and a psychiatrist, who were fluent in English and Turkish, produced and evaluated the first Turkish translation (Turkish Translation 1).

\section{Back translation}

Assessment of the versions was performed using a double-blind process involving the translator and back translator. A linguist, who was a postgraduate student with no knowledge of the original English questionnaire and familiar with quality-of-life terminology, back translated the Turkish version of the PIDAQ into English. A committee composed of a native English speaker, who was fluent in Turkish, and two linguists compared the 
original and back-translated versions. Turkish Translation 11 was developed based on the committee's suggestions and proposals (Appendices 1 and 2).

\section{Cross-cultural adaptation}

A committee consisting of two orthodontists, two postgraduate students, a dentist, and a psychiatrist, all of whom were fluent in English and familiar with quality-of-life terminology, were asked to evaluate the scale with respect to cultural relevance, purpose, and clarity. Semantic and conceptual equivalence were assessed once the final revision and Turkish Translation 111 were developed.

\section{Pilot study}

The final version of the translation was pretested by 30 young adults ( 14 women and 16 men) aged 18-30 years, from the Sifa University Faculty of Medicine. Interviews were conducted by one investigator (FD), to prevent possible differences in explanations concerning the questionnaire. In congruence with the questionnaires, Turkish Translation 11l, the final Turkish version of the PIDAQ, did not undergo modification.

\section{Measurements used to assess the validity and reliability of the PIDAO}

All participants were asked to indicate their need for orthodontic treatment.

\section{Aesthetic component of the Index of Orthodontic Treatment Need}

The aesthetic component of the Index of Orthodontic Treatment Need (10TN-AC) was used to determine individuals' self-perception concerning their dental aesthetics. Participants were asked to rate the extent to which 10 black and white photographs of anterior teeth demonstrating varying amount of malocclusion resembled their dentition. ${ }^{14}$

\section{Perception of Occlusal Scale}

The Perception of Occlusal Scale (POS) contains six items that indicate the occlusal traits of the anterior region, with responses recorded using a five-point Likert scale in a similar manner to that of the PIDAQ. ${ }^{7}$

\section{Retest}

Thirty students, who were randomly selected (with the help of nicknames), completed the questionnaires in a test-retest assessment performed three weeks subsequent to pretesting, to determine reliability.

\section{Statistical analysis}

The Statistical Package for Social Sciences (SPSS Inc., 17.0, Chicago, IL, USA) was used to analyze all data.
A factor analysis of the scale was performed using principal components analysis and varimax rotation with Kaiser normalization, to determine structural validity. The internal consistency of the Turkish version of the PIDAQ was assessed by calculating Cronbach's alpha coefficients for the subscales. Distribution of the variables was assessed via the Kolmogorov-Smirnov method. PIDAQ subscale and total scores were compared with self-reported of the IOTN-AC and POS via an ANOVA and the Kruskal-Wallis test. Test-retest reliability was assessed via Spearman's correlation coefficients using correlations between PIDAQ subscale and total scores for determined using correlations between awareness, and satisfaction. An independent samples t-test was performed to compare PIDAQ scores and self-evaluation of orthodontic treatment need.

To facilitate the interpretation of the results, the scores for items concerning dental self-confidence (items 1-6) were reversed. The level of significance was set at $p<0.05$.

\section{RESULTS}

The study included 284 individuals, of whom 260 returned questionnaires with no missing data, which were included in the analysis (age range, $18-30$ years; mean age, $20.50 \pm 1.9$ years). Sex distribution was almost equal: the proportions of men and women were $47.3 \%(n=123)$ and 52.7\% (137), respectively. A need for orthodontic treatment was reported by 96 individuals (36.9\%).

\section{Cross-cultural adaptation}

Subsequent to the implementation of two changes via the translation process, the translation committee considered the Turkish translation of the PIDAQ semantically and conceptually equivalent to the original. Therefore, cross-cultural adaptation resulted in a tool that was ready for use.

\section{Construct validity}

The Kaiser-Meyer-Olkin measure of sampling adequacy was 0.901, and the Bartlett's test of sphericity was significant $(2,740.1 ; p<0.001)$. These results showed that the variables were within the normal range and appropriate for inclusion in factor analysis. Four factor structures were extracted in an explanatory factor analysis, with the item factor loadings ranging from 0.380 to 0.868 . Sixty-two percent of the four subscale variance reproducing the original PIDAQ. Few questions were shuffled among domains various factor loadings with components are shown in Table 1.

\section{Reliability}

Cronbach's alpha internal consistency coefficients for the subscales ranged from 0.534 to 0.904 . Cumulative 
Table 1. Factor loadings of the PIDAQ item scale scores with the reliability of the scales (Cronbach's $\alpha$ )

\begin{tabular}{|c|c|c|c|c|}
\hline \multirow{2}{*}{ Scale item } & \multicolumn{4}{|c|}{ Component as extracted by factor analysis } \\
\hline & Dental self-confidence & Social impact & Psycological impact & Aesthetic attitude \\
\hline \multicolumn{5}{|l|}{ Dental self-consciousness } \\
\hline Proud of my teeth & $0.828^{*}$ & 0.150 & 0.123 & 0.200 \\
\hline Like to show teeth & $0.781^{*}$ & 0.111 & 0.077 & 0.235 \\
\hline Pleased to see teeth in the mirror & $0.555^{*}$ & 0.052 & 0.047 & 0.194 \\
\hline Teeth are attractive & $0.868^{*}$ & 0.186 & 0.101 & 0.091 \\
\hline Satisfied with appearance & $0.836^{*}$ & 0.203 & 0.102 & 0.164 \\
\hline Find tooth position nice & $0.810^{*}$ & 0.098 & 0.179 & 0.122 \\
\hline \multicolumn{5}{|l|}{ Social impact } \\
\hline Hold back when I smile & 0.216 & $0.640^{*}$ & 0.114 & 0.215 \\
\hline What others think & 0.164 & $0.806^{*}$ & 0.156 & 0.151 \\
\hline Offensive remarks & 0.173 & $0.812^{*}$ & 0.100 & 0.180 \\
\hline Inhibited in social & 0.140 & $0.754^{*}$ & -0.020 & 0.314 \\
\hline Hide my teeth & 0.110 & $0.539^{*}$ & 0.140 & 0.057 \\
\hline People stare & 0.054 & $0.655^{*}$ & 0.079 & 0.336 \\
\hline \multicolumn{5}{|l|}{ Psycological impact } \\
\hline Irritated on remarks & -0.068 & 0.317 & $0.380^{*}$ & 0.110 \\
\hline Envy & 0.156 & 0.164 & $0.696^{*}$ & 0.301 \\
\hline Others have nicer teeth & 0.163 & 0.115 & $0.738^{*}$ & 0.021 \\
\hline Wish teeth looked better & 0.229 & 0.032 & $0.729^{*}$ & 0.245 \\
\hline \multicolumn{5}{|l|}{ Aesthetic attitude } \\
\hline Worry about opposite sex & 0.056 & 0.331 & 0.178 & $0.540^{*}$ \\
\hline Somewhat distressed & 0.106 & 0.225 & 0.371 & $0.673^{*}$ \\
\hline Somewhat unhappy & 0.252 & 0.217 & 0.259 & $0.748^{*}$ \\
\hline Feel bad & 0.263 & 0.250 & -0.120 & $0.811^{*}$ \\
\hline Don't like teeth in mirror & 0.446 & 0.186 & 0.318 & $0.649^{*}$ \\
\hline Don't like teeth in photo & 0.427 & 0.267 & 0.208 & $0.605^{*}$ \\
\hline Don't like teeth on video & 0.399 & 0.333 & 0.198 & $0.611^{*}$ \\
\hline Cronbach's $\alpha$ & 0.823 & 0.806 & 0.534 & 0.904 \\
\hline$\%$ of variance & 20.205 & 16.455 & 16.333 & 9.946 \\
\hline Cumulative $\%$ of variance & 20.205 & 36.660 & 52.993 & 62.939 \\
\hline
\end{tabular}

PIDAQ, Psychosocial Impact of Dental Aesthetics Questionnaire.

*Salient factor loadings.

variance for the entire scale was $62.94 \%$ (Table 1).

\section{Reproducibility}

In the test-retest reliability analysis, Spearman's correlation was used to analyze data from 30 individuals, which were compared with data obtained three weeks later. The test-retest reliability coefficient for the scale was high $(r=0.863, p<0.001)$. PIDAQ scores did not differ significantly between the first and second tests.

\section{Discriminant validity}

PIDAQ subscale and total scores differed significantly according to 1OTN-AC and POS scores (Tables 2 and 3 ) and self-reported orthodontic treatment need ( $p$ $\leq$ 0.001; Table 4). Men exhibited significantly higher scores relative to those of women, who did not express a need for orthodontic treatment via the dental selfconsciousness subscale ( $p<0.001$; Table 4$)$. 
Table 2. Comparison PIDAQ scale scores according to IOTN-AC scores and the relationships between the PIDAO domains and IOTN-AC

\begin{tabular}{|c|c|c|c|c|c|}
\hline $\begin{array}{l}\text { IOTN-AC } \\
\text { Score }\end{array}$ & $\begin{array}{c}\text { Dental self- } \\
\text { consciousness }^{\beta}\end{array}$ & $\begin{array}{c}\text { Social } \\
\text { impact }\end{array}$ & $\begin{array}{c}\text { Psycological } \\
\text { impact }\end{array}$ & $\begin{array}{l}\text { Aesthetic } \\
\text { attitude }\end{array}$ & Total \\
\hline $1(n=102)$ & $8.42 \pm 6.62^{b}$ & $5.57 \pm 6.34^{\mathrm{a}}$ & $6.63 \pm 5.61^{\mathrm{a}}$ & $7.15 \pm 5.95^{\mathrm{c}}$ & $28.02 \pm 17.5^{\mathrm{c}}$ \\
\hline $2(\mathrm{n}=76)$ & $12.29 \pm 5.79^{\mathrm{a}}$ & $6.90 \pm 5.49^{\mathrm{ab}}$ & $8.60 \pm 5.24^{\mathrm{a}}$ & $9.38 \pm 5.56 b^{c}$ & $37.18 \pm 15.0^{\mathrm{c}}$ \\
\hline $3(\mathrm{n}=38)$ & $14.20 \pm 5.20^{\mathrm{a}}$ & $9.79 \pm 6.37^{\mathrm{a}}$ & $9.54 \pm 3.71^{\mathrm{a}}$ & $13.04 \pm 6.62^{\mathrm{ab}}$ & $46.58 \pm 18.2^{\mathrm{ab}}$ \\
\hline$\geq 4(\mathrm{n}=30)$ & $15.39 \pm 6.63^{\mathrm{a}}$ & $9.64 \pm 6.70^{\mathrm{a}}$ & $9.60 \pm 4.10^{\mathrm{a}}$ & $13.53 \pm 8.0^{\mathrm{a}}$ & $48.17 \pm 20.2^{\mathrm{a}}$ \\
\hline ANOVA & $<0.001^{\dagger}$ & $0.003^{\dagger}$ & $0.009^{\dagger}$ & $<0.001^{*}$ & $<0.001^{\ddagger}$ \\
\hline Spearman correlation & $\begin{aligned} \mathrm{r} & =0.391 \\
p & <0.001^{\text {}}\end{aligned}$ & $\begin{aligned} \mathrm{r} & =0.258 \\
p & <0.001^{\ddagger}\end{aligned}$ & $\begin{aligned} r & =0.226 \\
p & =0.001^{\ddagger}\end{aligned}$ & $\begin{aligned} r & =0.369 \\
p & <0.001^{*}\end{aligned}$ & $\begin{aligned} r & =0.413 \\
p & <0.001^{*}\end{aligned}$ \\
\hline
\end{tabular}

Values are presented as mean \pm standard deviation.

PIDAQ, Psychosocial Impact of Dental Aesthetics Questionnaire; IOTN-AC, Index of Orthodontic Treatment Need.

a,b,c,d Bonferroni post-hoc test; different letters indicate statistically significant differences between columns.

${ }^{*} p<0.05,{ }^{\dagger} p<0.01,{ }^{\dagger} p<0.001$.

${ }^{\beta}$ Scores were reversed.

Table 3. Results of a one-way ANOVA comparing PIDAQ scale scores according to POS scores, and Spearman correlation coefficients for the relationships between the PIDAQ domains and POS

\begin{tabular}{lccccc}
\hline \multicolumn{1}{c}{$\begin{array}{c}\text { POS } \\
\text { Scores }\end{array}$} & $\begin{array}{c}\text { Dental self- } \\
\text { consciousness }^{\beta}\end{array}$ & $\begin{array}{c}\text { Social } \\
\text { impact }\end{array}$ & $\begin{array}{c}\text { Psycological } \\
\text { impact }\end{array}$ & $\begin{array}{c}\text { Aesthetic } \\
\text { attitude }\end{array}$ & Total \\
\hline $0-1(\mathrm{n}=75)$ & $7.33 \pm 7.78^{\mathrm{b}}$ & $3.81 \pm 4.53^{\mathrm{b}}$ & $4.60 \pm 4.06^{\mathrm{b}}$ & $5.51 \pm 5.47^{\mathrm{b}}$ & $21.68 \pm 16.62^{\mathrm{b}}$ \\
$2-4(\mathrm{n}=64)$ & $7.46 \pm 5.98^{\mathrm{b}}$ & $4.23 \pm 7.33^{\mathrm{b}}$ & $8.19 \pm 7.02^{\mathrm{a}}$ & $5.69 \pm 3.74^{\mathrm{b}}$ & $25.57 \pm 14.28^{\mathrm{b}}$ \\
$5-8(\mathrm{n}=55)$ & $12.48 \pm 6.87^{\mathrm{a}}$ & $7.24 \pm 5.92^{\mathrm{ab}}$ & $7.79 \pm 3.96^{\mathrm{a}}$ & $8.38 \pm 5.19^{\mathrm{b}}$ & $35.91 \pm 15.25^{\mathrm{a}}$ \\
$\geq 9(\mathrm{n}=52)$ & $13.11 \pm 5.43^{\mathrm{a}}$ & $9.02 \pm 6.11^{\mathrm{a}}$ & $9.28 \pm 5.13^{\mathrm{a}}$ & $12.60 \pm 7.11^{\mathrm{a}}$ & $44.03 \pm 18.66^{\mathrm{a}}$ \\
ANOVA & $<0.001^{\ddagger}$ & $<0.001^{\ddagger}$ & $<0.001^{\ddagger}$ & $<0.001^{\ddagger}$ & $<0.001^{\ddagger}$ \\
Spearman correlation & $\mathrm{r}=0.352$ & $\mathrm{r}=0.332$ & $\mathrm{r}=0.291$ & $\mathrm{r}=0.432$ & $\mathrm{r}=0.460$ \\
& $p<0.001^{\ddagger}$ & $p<0.001^{\ddagger}$ & $p<0.001^{\ddagger}$ & $p<0.001^{\ddagger}$ & $p<0.001^{\ddagger}$ \\
\hline
\end{tabular}

Values are presented as mean \pm standard deviation.

PIDAQ, Psychosocial Impact of Dental Aesthetics Questionnaire; POS, Perception of Occlusal Scale.

a,b,c,d Bonferroni post-hoc test; different letters indicate statistically significant differences between columns.

${ }^{*} p<0.05,{ }^{\dagger} p<0.01,{ }^{\dagger} p<0.001$.

${ }^{\beta}$ Scores were reversed.

Table 4. PIDAO scale scores according to orthodontic treatment need

\begin{tabular}{|c|c|c|c|c|c|c|c|}
\hline & \multicolumn{3}{|c|}{ Demand for orthodontic treatment } & \multicolumn{3}{|c|}{ Do not demand for orthodontic treatment } & \multirow{2}{*}{$p$-value } \\
\hline & Male & Female & $p$-value & Male & Female & $p$-value & \\
\hline Dental self-consciousness $^{\beta}$ & $12.16 \pm 6.70$ & $14.55 \pm 5.03$ & 0.95 & $12.06 \pm 6.69$ & $8.04 \pm 6.58$ & $0.001^{\ddagger}$ & $0.001^{\neq}$ \\
\hline Social impact & $10.61 \pm 6.51$ & $8.00 \pm 5.91$ & 0.86 & $5.96 \pm 4.84$ & $5.83 \pm 7.10$ & 0.901 & $<0.001^{\ddagger}$ \\
\hline Psycological impact & $9.35 \pm 3.52$ & $10.55 \pm 5.84$ & 0.32 & $6.81 \pm 5.96$ & $6.89 \pm 4.09$ & 0.936 & $<0.001^{\ddagger}$ \\
\hline Aesthetic attitude & $13.48 \pm 6.28$ & $12.73 \pm 7.57$ & 0.662 & $7.81 \pm 5.44$ & $7.06 \pm 5.89$ & 0.936 & $<0.001^{\ddagger}$ \\
\hline Total & $45.61 \pm 19.17$ & $45.84 \pm 18.33$ & 0.960 & $32.67 \pm 14.82$ & $27.83 \pm 18.68$ & 0.111 & $<0.001^{\ddagger}$ \\
\hline
\end{tabular}

Values are presented as mean \pm standard deviation.

PIDAQ, Psychosocial Impact of Dental Aesthetics Questionnaire.

Independent samples $t$-test; ${ }^{*} p<0.05,{ }^{\dagger} p<0.01,{ }^{\dagger} p<0.001$.

${ }^{\beta}$ Scores were reversed. 


\section{DISCUSSION}

Quality of life is commonly assessed via questionnaires, which should be verified for cross-cultural adaptation when the original and translated versions are comparable. ${ }^{15}$ Questionnaires are suitable for use in different cultural contexts only when they demonstrate good psychometric properties. The cultural adaptation approach used in the translation and validation was proposed by the International Quality of Life Assessment Project, ${ }^{16}$ to establish the Turkish version of the PIDAQ. According to the results of this study, the PIDAQ's internal consistency, factor structure, and correlations with other scales indicated that the scale is a valid and reliable assessment tool for use in the Turkish culture.

The study sample was homogenous with respect to sex and age. All participants were Faculty of Medicine students; therefore, the sample constituted a welleducated group. Dentistry students and individuals with experience of undergoing orthodontic treatment were excluded from the study, to prevent the inclusion of individuals with knowledge concerning orthodontics and ideal facial aesthetic norms.

To evaluate the equivalence of different language versions of a questionnaire, conceptual, semantic, technical, and psychometric issues require consideration. ${ }^{7}$ This meticulous process includes the following steps: translation, back translation, cultural adaptation, and pretesting. In this study, a translation committee composed of orthodontists, a psychiatrist, linguists, and a native English speaker performed translation and back translation, to ensure excellent translation and improved understanding and detect potential problems. Back translation showed that the translated version of the PIDAQ was very similar to the original. Similar processes were used in previous studies involving the translation and validation of the PIDAQ in different languages. ${ }^{6,7,13}$ Similarly, the pilot study showed good results and indicated that the quality of the translation was satisfactory.

Factor analysis is used to evaluate construct validity. ${ }^{7}$ Five components were extracted in principal component factor analysis with orthogonal rotation. Two components included only two items. One of the Cronbach's alpha values for the components was somewhat low (0.391), and some items did not demonstrate sufficient factor loading in the analysis. Factor analysis then tried fixing the number of components to four as in the original version, this form gave good item factor loading. The results indicated that the validity and reliability of the Turkish version of the PIDAQ in young adults was structured on four components, as in the original, Spanish, Brazilian, and Italian versions. ${ }^{4,5,12,13}$

The first component, dental self-confidence, was reported to have a significant impact on individuals' emotional states and has been found to represent subjective perception of well-being. ${ }^{17}$ This component demonstrated the highest explained variance of all components and was structured with the same items as those of the original version. ${ }^{5}$

The second component, social impact, included six items, while the original PIDAQ includes eight items. This component represents potential problems arising in social situations, because one perceives one's own dental appearance as unfavorable. The psychological impact factor loading for "Remarks about my teeth irritate me even when they are meant jokingly" was higher relative to that for social impact. In addition, the aesthetic concern factor loading for "1 sometimes worry about what members of the opposite sex think about my teeth" was higher relative to that for psychological impact. This result could demonstrate the importance of the opinions of members of the opposite sex with respect to aesthetic concerns.

In the Turkish version of the PIDAQ, aesthetic concern factor loadings for three items, "somewhat distressed," "somewhat unhappy," and "feel bad," were high. In the original version, these items were included under psychological impact. Therefore, the fourth component included psychological impact and aesthetic concern items. This result is quite similar to that for the Chinese version of the PIDAQ, in which it was known as "aesthetics attitude," defined as a state of mind or a feeling concerning aesthetics. Attitudes toward dental aesthetics could also reflect the need for orthodontic treatment. ${ }^{7}$ For this reason, the fourth factor was entitled "aesthetics attitude," as in the Chinese version.

Together, the four components accounted for 62.93\% of the total variance, which is above the minimum recommended threshold for a stable factor solution. ${ }^{18}$ Furthermore, the original PIDAQ components exhibited a total variance of $63.28 \%$, which is similar to the findings of a study conducted by Klages et al. ${ }^{5}$

Cronbach's alpha coefficient should be at least 0.70 for questionnaire reliability. ${ }^{19}$ Cronbach's alpha coefficients were rather high in Nepalese (0.965-0.988) and Chinese (0.905-0.917) populations, whereas considerably lower values were reported for Spanish (0.768-0.862) and Brazilian (0.75-0.91) populations. Cronbach's alpha coefficient for the Turkish version of the PIDAQ was similar to that for the original. ${ }^{5}$ Moreover, the internal consistency of three of four subscales in this study were strongly related (0.904-0.806), while the internal consistency for the psychological impact subscale was fair (0.534). Three items were moved from "Social impact" subscale to "Psychological impact" subscale and one item was removed from "Psychological impact" subscale to "Social impact" subscale. Lower internal 
consistency, relative to that of the original version, could be explained by the disarrangement of items in the psychological impact subscale.

In addition, "Remarks about my teeth irritate me even when they are meant jokingly" in the social impact subscale demonstrated the lowest factor loading of all items (0.380; Table 1), and this decreased the psychological impact subscale's Cronbach's alpha coefficient. This factor has quite similar factor load in social impact (0.317; Table 1) as it is under social impact subscale in the original version. In authors' opinion this item might evaluate in social impact subscale. However, as the psychological impact factor loading was a little higher for this item, it was excluded from the social impact subscale.

The test-retest correlation coefficient for the PIDAQ was high $(r=0.863)$ and could be considered excellent. Discriminant validity has been assessed using the POS and IOTN-AC in previous studies involving the translation and validation of the PIDAQ. ${ }^{4-7}$ In this study, these scales were used to verify the Turkish Version of the PIDAQ. Significant results indicated that higher PIDAQ values were correlated with higher POS and IOTN-AC values (Tables 2 and 3). Similar results were observed in studies using the same protocol for discriminant validity. ${ }^{4-6}$

While the 10TN-AC has been used widely, it does not contain items pertaining to Class 111 malocclusion. However, Sayin and Türkkahraman ${ }^{20}$ reported that approximately $11.5 \%$ of a Turkish population showed Class 111 malocclusion. The 10TN-AC has been used to rate deviation from malocclusion in the Turkish population. ${ }^{21}$ Despite this, failure to examine Class 111 malocclusion could be a limitation of this study. However, as mentioned above, the 10TN-AC is a widely used international scale. This should be considered when interpreting the results of the current study.

All participants indicated their treatment need and were assigned to one of two groups according to their self-perception of treatment need. PIDAQ subscale and total scores differed significantly between groups, suggesting that the scales differentiated between the two groups with respect to OHRQOL (Table 4). The results showed that men and women differed significantly only in the "no treatment need group," in which men exhibited significantly higher scores for the dental self-consciousness subscale relative to those of women. This result could indicate that although men's levels of dental self-consciousness were higher, their self-perception of orthodontic treatment need was low relative to that reported by women. This outcome is consistent with findings indicating that women show greater dissatisfaction and concern regarding their dental appearance relative to that of men. ${ }^{22}$ Contrary to the results of this study, men and women did not differ significantly in a study examining the Nepalese version of the PIDAQ. ${ }^{6}$ This difference could be attributed to cultural and ethnic differences between the two populations.

The PIDAQ was strongly correlated with satisfaction with personal dental appearance and weakly correlated with awareness of malocclusion (Table 4). This result indicated that the study population was particularly concerned with appearance and aesthetics, and the PIDAQ reflected this. This could have explained why awareness of malocclusion is poor in the Turkish population and affected by cultural differences and dental awareness. ${ }^{23}$

Satisfaction with physical appearance is personal and could depend on patients' psychological circumstances. Occasionally, objective and subjective evaluations of orthodontic treatment need differ. Therefore, one of the limitations of this study was the lack of professional evaluation of orthodontic treatment need using specially developed indices.

This study included university students from one of the largest cities in Turkey (lzmir), and the sample could be considered to involve adequate geographic, cultural, and ethnic diversity, because it included students from different regions of the country; it could therefore be regarded as representative of the general population.

\section{CONCLUSION}

The present study was important, as it was the first to examine the validity and reliability of the PIDAQ in a Turkish sample. The study provided a Turkish version of the PIDAQ, which could be a useful tool in the evaluation of the psychosocial impact of malocclusion in young Turkish adults.

\section{REFERENCES}

1. Goes PS, Watt R, Hardy RG, Sheiham A. The prevalence and severity of dental pain in 14-15 year old Brazilian schoolchildren. Community Dent Health 2007;24:217-24.

2. Sheiham A. Oral health, general health and quality of life. Bull World Health Organ 2005;83:644.

3. Bernabé E, Kresevic VD, Cabrejos SC, Flores-Mir F, Flores-Mir C. Dental esthetic self-perception in young adults with and without previous orthodontic treatment. Angle Orthod 2006;76:412-6.

4. Bucci R, Rongo R, Zito E, Galeotti A, Valletta R, D'Antò V. Cross-cultural adaptation and validation of the Italian Psychosocial Impact of Dental Aesthetics Questionnaire (PIDAQ). Qual Life Res 2015;24:747-52. 
5. Klages $\mathrm{U}$, Claus $\mathrm{N}$, Wehrbein $\mathrm{H}$, Zentner A. Development of a questionnaire for assessment of the psychosocial impact of dental aesthetics in young adults. Eur J Orthod 2006;28:103-11.

6. Singh VP, Singh R. Translation and validation of a Nepalese version of the Psychosocial Impact of Dental Aesthetic Questionnaire (PIDAQ). J Orthod 2014;41:6-12.

7. Lin H, Quan C, Guo C, Zhou C, Wang Y, Bao B. Translation and validation of the Chinese version of the psychosocial impact of dental aesthetics questionnaire. Eur J Orthod 2013;35:354-60.

8. Gherunpong S, Tsakos G, Sheiham A. A socio-dental approach to assessing children's orthodontic needs. Eur J Orthod 2006;28:393-9.

9. Birkeland K, Bøe OE, Wisth PJ. Relationship between occlusion and satisfaction with dental appearance in orthodontically treated and untreated groups. A longitudinal study. Eur J Orthod 2000;22:509-18.

10. Phillips C, Beal KN. Self-concept and the perception of facial appearance in children and adolescents seeking orthodontic treatment. Angle Orthod 2009;79:12-6.

11. Bellot-Arcís C, Montiel-Company JM, Almerich-Silla JM. Psychosocial impact of malocclusion in Spanish adolescents. Korean J Orthod 2013;43:193-200.

12. Montiel-Company JM, Bellot-Arcís C, AlmerichSilla JM. Validation of the psychosocial impact of dental aesthetics questionnaire (Pidaq) in Spanish adolescents. Med Oral Patol Oral Cir Bucal 2013;18:e168-73.

13. Sardenberg F, Oliveira AC, Paiva SM, Auad SM, Vale MP. Validity and reliability of the Brazilian version of the psychosocial impact of dental aesthetics questionnaire. Eur J Orthod 2011;33:270-5.

14. Brook PH, Shaw WC. The development of an index of orthodontic treatment priority. Eur J Orthod 1989;11:309-20.

15. Peters M1, Passchier J. Translating instruments for cross-cultural studies in headache research. Headache 2006;46:82-91.

16. Aaronson NK, Acquadro C, Alonso J, Apolone G, Bucquet D, Bullinger $\mathrm{M}$, et al. International Quality of Life Assessment (1QOLA) project. Qual Life Res 1992;1:349-51.

17. Klages U, Kianifard S, Ulusoy O, Wehrbein H. Anxiety sensitivity as predictor of pain in patients undergoing restorative dental procedures. Community Dent Oral Epidemiol 2006;34:139-45.

18. Streiner DL. Figuring out factors: the use and misuse of factor analysis. Can J Psychiatry 1994;39:135-40.

19. Polit DF, Hungler BP. Nursing research: principles and methods. 5th ed. Philadephia: Lippincott; 1995.

20. Sayin MO, Türkkahraman H. Malocclusion and crowding in an orthodontically referred Turkish population. Angle Orthod 2004;74:635-9.

21. Uçüncü N, Ertugay E. The use of the Index of Orthodontic Treatment need (10TN) in a school population and referred population. J Orthod 2001;28:45-52.

22. Tin-Oo MM, Saddki N, Hassan N. Factors influencing patient satisfaction with dental appearance and treatments they desire to improve aesthetics. BMC Oral Health 2011;11:6.

23. Altun C, Güven G, Başak F, Akbulut E. Evaluation of children in the age group of 6 to 11 with respect to oral-dental health. Gulhane Med J 2005;47:114-8. 
Appendix 1. Psychosocial Impact of Dental Aesthetics Questionnaire ${ }^{5}$

\section{Dental Self-Confidence}

1 am proud of my teeth.

1 like to show my teeth when 1 smile.

1 am pleased when 1 see my teeth in the mirror.

My teeth are attractive to others.

1 am satisfied with the appearance of my teeth.

1 find my tooth position to be very nice.

Social Impact

1 hold myself back when 1 smile so my teeth don't show so much.

If 1 don't know people well, 1 am sometimes concerned about what they might think about my teeth.

I'm afraid that other people could make offensive remarks about my teeth.

1 am somewhat inhibited in social situations, because of my teeth.

1 sometimes catch myself holding my hand in front of my mouth to hide my teeth.

Sometimes, 1 think people are staring at my teeth.

Remarks about my teeth irritate me, even when they are meant jokingly.

1 sometimes worry about what members of the opposite sex think about my teeth.

Psychological Impact

1 envy the nice teeth of other people.

1 am somewhat distressed when 1 see other people's teeth.

Sometimes, 1 am somewhat unhappy about the appearance of my teeth.

1 think that most people 1 know have nicer teeth than 1 do.

1 feel bad when 1 think about what my teeth look like.

1 wish my teeth looked better.

\section{Aesthetic Concern}

1 don't like to see my teeth in the mirror.

1 don't like to see my teeth in photographs.

1 don't like to see my teeth when 1 look at a video of myself. 


\section{Appendix 2. Dental Estetiğin Psikososyal Etkisi Ölçeği}

\section{Dental özgüven}

Dişlerimle gurur duyarım

Gülümserken dişlerimi göstermeyi severim

Aynaya baktı̆ı̆ımda dişlerimin görüntüsünden memnun oluyorum

Dişlerim çevremdekiler tarafından beğenilir

Dişlerimin görüntüsü beni tatmin eder

Dişlerimin pozisyonlarının çok güzel olduğunu düşünüyorum

Sosyal etki

Gülümsediğimde dişlerim çok fazla görünmesin diye kendimi tutuyorum

Bazen tanımadığım insanların dişlerim hakkındaki düşünceleri beni kaygılandırıyor

Başkalarının dişlerim ile dalga geçmesinden korkarım

Dişlerimden dolayı bazen sosyal ilişkilerimi sınırlıyorum

Bazen elimle dişlerimi kapattı̆̆ımı farkediyorum

Bazen insanların dişlerime dikkatlice baktığını düşünüyorum

Psikolojik etki

Dişlerimle dalga geçilmesi beni rahatsız eder

Başkalarının dişlerine imreniyorum

Diğer insanların benden daha hoş dişleri olduğunu düşünüyorum

Dişlerimin daha iyi görünmesini isterdim

Estetik tutum

Bazen karşı cinsden insanların dişlerim hakkındaki düşüncelerinden endişeleniyorum

Diğer insanların dişlerini gördügüumde biraz üzülüyorum

Bazen dişlerimin görüntüsü nedeniyle biraz mutsuz oluyorum

Dişlerimin görüntüsü aklıma geldiğinde kendimi kötü hissediyorum

Aynaya baktığımda dişlerimi beğenmiyorum

Fotoğraflarda dişlerimi görmek istemiyorum

Kendime ait bir video izlediğimde dişlerimi görmekten hoşlanmıyorum 